\title{
AVALIAÇÃO DA SEMENTE DE MORINGA OLEIFERA LAM COMO BIOSSORVENTE PARA REMOÇÃO DE DIURON
}

\author{
H. K. S. SOUZA ${ }^{1 *}$, P. F. COLDEBELLA ${ }^{1}$, L. NISHI ${ }^{1}$, R. BERGAMASCO ${ }^{1}$, M. F. VIEIRA ${ }^{1}$, A. M. \\ S. VIEIRA ${ }^{2}$ \\ ${ }^{1}$ Universidade Estadual de Maringá, Departamento de Engenharia Química \\ ${ }^{2}$ Universidade Estadual de Maringá, Departamento de Engenharia de Alimentos \\ *e-mail: karolspricigo@hotmail.com
}

\begin{abstract}
RESUMO
Tecnologias convencionais de tratamento de água, como a coagulação-floculação, sedimentação, filtração convencional e desinfecção, não são suficientes para remover concentrações muito baixas de pesticidas. A Moringa Oleifera Lam (M. oleifera) é um importante material natural que pode ser usado como adsorvente de contaminantes orgânicos da água. Neste estudo avaliou a capacidade de adsorção da semente de $M$. oleifera para remoção do herbicida Diuron de soluções aquosas. Soluções de $5 \mathrm{mg} \mathrm{L}^{-1}$ de Diuron foram preparadas e analisadas por Cromatografia Liquida de Alta Eficiência. Vários fatores que influenciam a adsorção foram testados, tais como: quantidade de adsorvente, tempo de contato, $\mathrm{pH}$, temperatura, tamanho de partícula do adsorvente e velocidade de agitação. A partir dos experimentos realizados foi possível verificar que a máxima capacidade de adsorção da semente de $M$. oleifera foi obtida em 60 minutos e com esse tempo conseguiu-se uma eficiência de remoção de diuron de até $67 \%$. Os resultados também mostraram que os fatores que influenciaram diretamente na adsorção de diuron foram a massa de adsorvente, a temperatura e a velocidade de agitação e que quanto maior a quantidade de massa, a velocidade de agitação e a temperatura maior a remoção de diuron das soluções contaminadas.A preparação simples e os resultados experimentais satisfatórios indicaram que a semente de $M$. oleifera é um material natural promissor para a remoção de poluentes orgânicos.
\end{abstract}

\section{INTRODUÇÃO}

$\mathrm{O}$ uso de pesticidas ajuda a aumentar a produtividade das culturas, mas os seus resíduos na água, solo e ar causam grandes problemas para o meio ambiente e a saúde humana.

O Diuron, N-(3,4-diclorofenil)-N, Ndimetil-ureia, é um herbicida pertencente à família fenilamida e da subclasse de fenilureia (GIACOMAZZI e COCHET, 2004). É conhecido como um herbicida fotossistema II (PSII), que perturba a capacidade da planta para a fotossíntese (HOLMES, 2014). No
Brasil, o Diuron é usado principalmente nas culturas de cana-de-açúcar, soja e algodão.

O Diuron é relativamente persistente no solo, com uma meia-vida de 1 mês a 1 ano. A sua persistência no solo é devido a uma combinação de três propriedades: a estabilidade química, baixa solubilidade em água e forte adsorção às partículas do solo (GOODDY, CHILTON e HARRISON, 2002). Segundo Chen e Young (2009), o Diuron é um dos herbicidas mais usados na Califórnia (EUA) e tem sido frequentemente detectado nas águas de abastecimento.

O limite máximo permitido de resíduos de Diuron em água para consumo humano no 
Brasil é de $90 \quad \mu \mathrm{g} \quad \mathrm{L}^{-1} \quad$ (PORTARIA 2914/2011).

As tecnologias convencionais de tratamento de água, como a coagulaçãofloculação, sedimentação, filtração convencional e desinfecção, não são suficientes para remover concentrações muito baixas de pesticidas na ordem de partes por bilhão (ppb).Processos alternativos tais como o uso de coagulantes naturais, biossorção e separação por membranas, têm apresentado resultados promissores na remoção de herbicidas de águas.

A biossorção é um processo alternativo bastante interessante já que suas principais vantagens são: baixo custo, alta eficiência e minimização de produtos químicos e/ou lodo biológico.

Surge, então, a Moringa oleifera Lam (M. oleifera), uma planta originária do noroeste indiano, rica em proteína e lipídeos. É bastante usada na alimentação, indústria e medicina. Ela também tem sido estudada como adsorvente natural. As sementes de $M$. oleífera se destacam pela sua capacidade coagulante, desempenhando um papel importantíssimo na busca por tratamentos alternativos da água.

Neste estudo, foi avaliada a capacidade da semente de $M$. oleifera no processo de biossorção para a remoção de Diuron de águas contaminadas.

\section{MATERIAIS E MÉTODOS}

\subsection{Preparação do Adsorvente}

A semente da $M$. oleifera foi triturada em liquidificador e seca em estufa a $40^{\circ} \mathrm{C}$ até peso constante. Em seguida, foi peneirada em diferentes tamanhos de malha da série de peneiras Tyler $(850-150 \mu \mathrm{m})$ em um agitador tipo magnético.

\subsection{Experimentos de Adsorção}

Para os experimentos de adsorção, águas contaminadas com $5 \mathrm{mg} / \mathrm{L}$ de Diuron foram preparadas a partir do produto comercial 500 g/L (500 SC, Nortox, Brasil) em água de osmose inversa.

Primeiramente, foi estudado o tempo de contato entre o adsorvente e o adsorbato. $\mathrm{O}$ estudo foi realizado em batelada e foi conduzido fixando, a temperatura de $25^{\circ} \mathrm{C}$, a granulometria do adsorvente de $500 \mu \mathrm{m}$, a massa de adsorvente de $0,5 \mathrm{~g}$, velocidade de agitação de $100 \mathrm{rpm}$, volume de solução de contaminante de $25 \mathrm{~mL}$ e $\mathrm{pH}$ de 6,5. O experimento foi realizado em incubadora com agitação orbital durante 24 horas. As amostras foram coletadas em vários intervalos de tempo, filtradas em filtro de acetato de celulose de $0,45 \mu \mathrm{m}$ e analisadas em cromatografia líquida de alta eficiência (CLAE), Marca Gilson controlado pelo Software Born, equipado com injetor manual Rheodyne, com volume de injeção de $20 \mu \mathrm{L}$, (bomba modelo 307), (detector UV/visível modelo 151) em leitura de $247 \mathrm{~nm}$. A análise foi conduzida utilizando como fase móvel acetonitrila/água, com relação (65/35) e

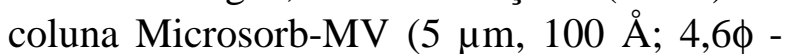
$250 \mathrm{~mm}$ ) com vazão de $0,75 \mathrm{mLmin}^{-1} \mathrm{em}$ temperatura de $35^{\circ} \mathrm{C}$. Os cálculos dos teores de Diuron foram realizados via construção de curvas de calibração.

Depois de analisar o tempo de contato de adsorção foram avaliados os seguintes parâmetros: granulometria do adsorvente, velocidade de agitação, $\mathrm{pH}$, temperatura e massa de adsorvente. Foi utilizado um delineamento de experimentos (delineamento de Plackett-Burman), que permite identificar as variáveis que impactam significativamente no processo de adsorção. $\mathrm{O}$ design do planejamento foi de $2^{4}$ com ponto central. Os ensaios foram realizados em duplicata e o ponto central foi realizado em três réplicas.

Para o efeito da granulometria do adsorvente foram avaliados os tamanhos 500, 300 e $180 \mu \mathrm{m}$. A velocidade de agitação foi variada em 100, 150 e $200 \mathrm{rpm}$. O pH da solução inicial foi avaliado em 4,7 e 10. A 
temperatura em 25,35 e $45^{\circ} \mathrm{C}$. A massa de adsorvente em 0,$1 ; 0,3$ e $0,5 \mathrm{~g}$. Os experimentos foram realizados com volume de solução de $25 \mathrm{~mL}$.

\section{RESULTADOS E DISCUSSÕES}

A primeira etapa do estudo consistiu em analisar o tempo de contato entre o adsorvente e o adsorbato durante 24 horas. A figura 1 mostra o resultado obtido. Os tempos de coleta de amostra para a análise foram: 10, 30, $60,120,240$ e 1440 minutos.

Figura 1- Porcentagem de adsorção de Diuron em relação ao tempo de contato com o adsorvente

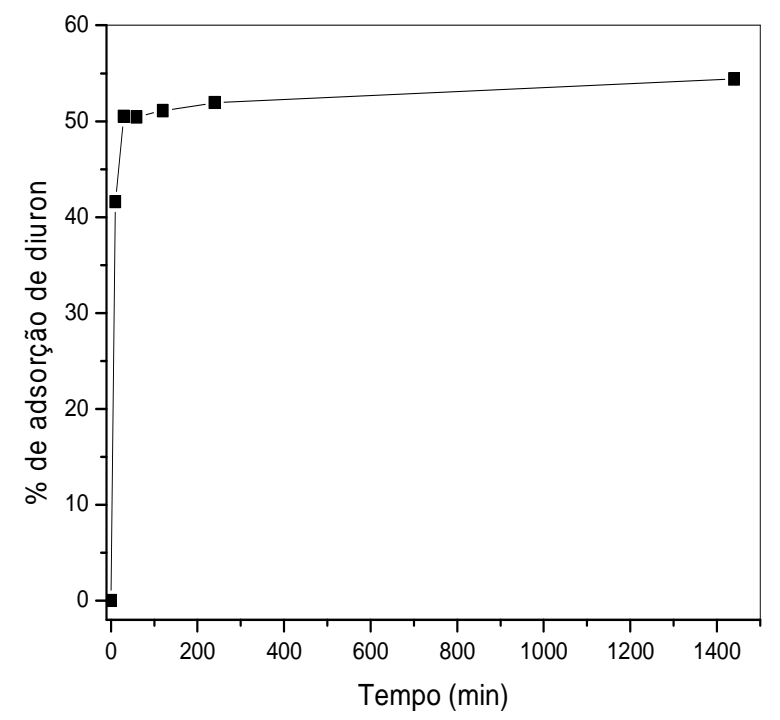

A partir dos resultados obtidos, observase que a adsorção de Diuron aumenta drasticamente nos primeiros 10 minutos. Isto é devido à presença de grande número de locais vazios na semente de $M$. oleifera. Com o aumento do tempo, a adsorção de Diuron aumenta, mas de forma menos intensa devido ao acúmulo deste nos sítios vagos do adsorvente. Esta adsorção de Diuron vai até o momento em que se tem o equilíbrio, onde o aumento do tempo de contato não vai fazer com que haja aumento da adsorção de Diuron.
Por meio da Figura 1, pode-se verificar que com $60 \mathrm{~min}$ se estabelece o estado de equilíbrio, e, portanto, este tempo foi utilizado nos demais experimentos.

Para avaliar os efeitos que podem ocorrer nos ensaios de adsorção foram analisados os parâmetros granulometria do adsorvente, velocidade de agitação, $\mathrm{pH}$, temperatura e massa de adsorvente.

A partir dos dados experimentais, uma análise estatística de Variância (ANOVA One Way) foi realizada a fim de verificar quais efeitos foram significativos no processo de adsorção do Diuron. Os parâmetros avaliados são significativos quando $\mathrm{p}$-valor $<0,05 \mathrm{com}$ nível de confiança de $95 \%$.

Na Tabela 1 são apresentados os parâmetros e seus respectivos p-valor e efeito. Quando o efeito é positivo significa que a resposta está aumentando com o aumento do fator avaliado, e quando ele é negativo significa que a resposta está aumentando com a diminuição do fator avaliado.

Tabela 1 - Valores de p-valor e efeito para os parâmetros analisados para a adsorção de Diuron.

\begin{tabular}{lcc}
\hline \multicolumn{1}{c}{ Parâmetros } & p-valor & Efeito \\
\hline Massa de adsorvente $(\mathrm{g})$ & 0,000000 & 27,42 \\
Granulometria $(\mathrm{mm})$ & 0,066564 & $-3,19$ \\
pH & 0,241981 & 2,00 \\
Temperatura $\left({ }^{\circ} \mathrm{C}\right)$ & 0,000001 & 10,62 \\
Velocidade de Agitação & 0,008383 & 4,75 \\
$(\mathrm{rpm})$ & &
\end{tabular}

Observa-se na Tabela 1 que os parâmetros que são significativos para a semente de $M$. oleifera na adsorção de Diuron (p-valor < 0,05) são: massa de adsorvente, temperatura e velocidade de agitação. A granulometria do adsorvente e o pH da solução inicial não foram significativos, ou seja, a adsorção de Diuron pela semente de $M$. oleifera não é dependente destes fatores. Ainda na Tabela é possível verificar que somente para a granulometria o efeito é negativo, ou seja, quanto menor a partícula 
maior a adsorção de Diuron. Para todos os outros parâmetros, o efeito é positivo, ou seja, quanto maior esse fator maior será a remoção de Diuron.

Não era esperado que a granulometria do adsorvente não fosse significativa para a adsorção do Diuron, já que quanto menor a partícula maior a área de contato entre $o$ adsorvente e a solução contaminada e assim maior a adsorção (o efeito para a granulometria mostra isso). Este fato, provavelmente, se deve as características do adsorvente.

A massa foi o parâmetro que teve o maior efeito e quanto maior a massa maior foi a adsorção de Diuron, pois quanto maior a quantidade de massa maior será a quantidade de sítios vagos, portanto maior a remoção. A Figura 2 apresenta um gráfico de superfície onde é possível verificar a influência que a massa de adsorvente e a granulometria tem na remoção de Diuron.

Figura 2- Eficiência de remoção de Diuron em relação a massa e a granulometria de adsorvente

\section{Eficiência de Remoção Diuron (\%) = 20,5322+68,5531* $x-9,1275^{*} y$}

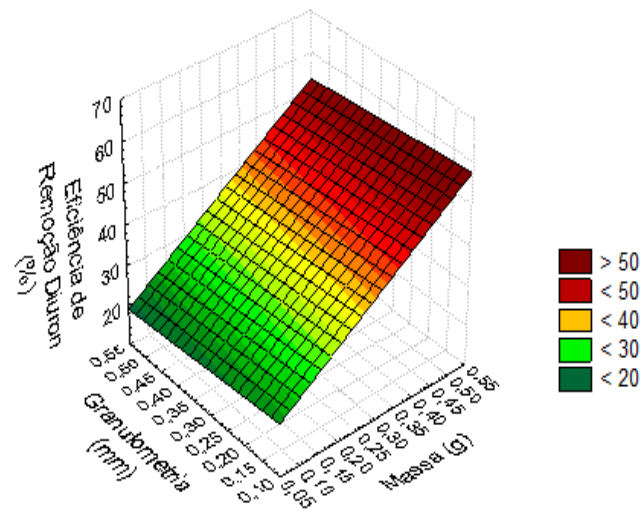

A partir da Figura 2, é possível observar que quanto maior a granulometria menor a eficiência de remoção, mas que a diferença entre as remoções entre as diferentes granulometrias é muito pequena, por isso este parâmetro não é significativo na adsorção de
Diuron. Já para a massa, pode-se verificar uma grande diferença na remoção de Diuron quando se varia este parâmetro. Quanto maior a massa maior a eficiência, mostrando que o p-valor e o efeito estão condizentes com este dado.

O processo de adsorção é fortemente influenciado pelo $\mathrm{pH}$ quando o contaminante pode se dissociar e liberar cargas no meio. No caso do Diuron, que não se dissocia em meio aquoso, provavelmente a adsorção ocorra por interações hidrofóbicas e por isso o $\mathrm{pH}$ não teve influência significativa na adsorção. Para mostrar o efeito do $\mathrm{pH}$ no estudo realizado é apresentado a Figura 3 que mostra a influência do $\mathrm{pH}$ e da massa de adsorvente na eficiência de remoção do Diuron.

Figura 3- Eficiência de remoção de Diuron em relação ao pH da solução inicial e a granulometria de adsorvente

Eficiência de Remoção Diuron $(\%)=15,2495+68,5531^{\star} x+0,3337^{*} y$

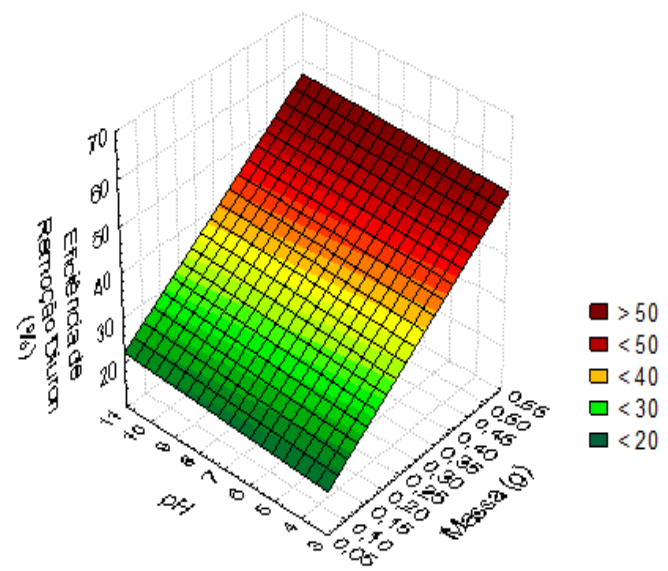

Pode-se verificar que quanto maior o pH maior a eficiência de remoção de Diuron, mas que a diferença de remoção entre os $\mathrm{pH}$ foi muito pequena. Comparando-se a Figura 2 com a 3 , pode-se verificar que a diferença da porcentagem de remoção do Diuron com a variação de $\mathrm{pH}$ foi menor que a diferença obtida pela granulometria, foi isso que $\mathrm{o}$ efeito de cada um desses parâmetros mostrou na Tabela 1 . 
A seguir, é apresentado um gráfico onde é possível visualizar o perfil da temperatura e da massa de adsorvente em relação a eficiência de remoção do Diuron.

Figura 4-Eficiência de remoção de Diuron em relação a massa de adsorvente e a temperatura

Eficiência de Remoção Diuron $(\%)=-0,9924+68,5531^{*} x+0,5308^{*} y$

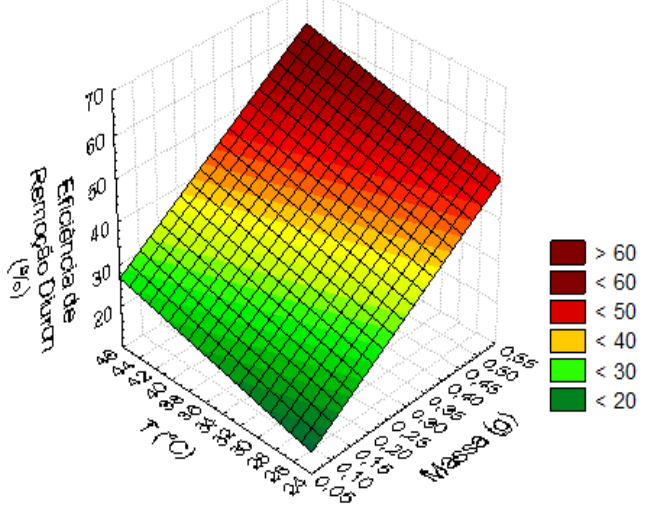

Por meio da Figura 4, é possível verificar a influência que a temperatura tem na eficiência da remoção de Diuron. Percebese uma maior eficiência de remoção quando se tem temperaturas mais altas. $\mathrm{O}$ efeito da temperatura não chega ser igual ao da massa, mas é maior que a do $\mathrm{pH}$ e granulometria. Como houve um aumento da remoção de Diuron com o aumento de temperatura, indica que o processo de adsorção é endotérmico.

Por fim, a velocidade de agitação. O efeito de aumentar a velocidade de agitação é diminuir a camada limite e, assim, a resistência do filme de transferência de massa circundante as partículas do adsorvente (MCKAY; OTTERBURN e SWEENEY, 1980).

A Figura 5 apresenta a eficiência de remoção do Diuron em relação à velocidade de agitação e massa de adsorvente.
Figura 5- Eficiência de remoção de Diuron em relação a velocidade de agitação e a massa de adsorvente

Eficiência de Remoção Diuron $(\%)=10,4589+68,5531^{*} x+0,0475^{*} y$

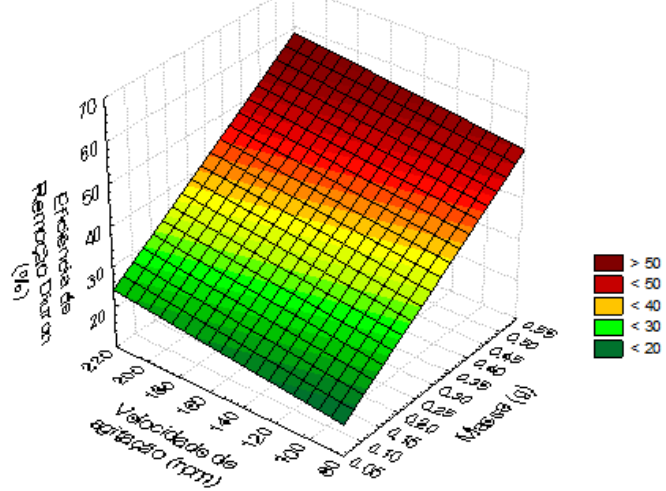

Observando a Figura 5, verifica-se que a velocidade de agitação tem influência na eficiência de adsorção do Diuron e que quanto mais agitada a solução e o soluto, maior a quantidade removida, pois quanto mais agitadas as partículas do adsorvente e as moléculas do adsorbato maior será a movimentação destas na solução, resultando assim numa maior chance de se ter a adsorção, por isso, quanto maior a velocidade de agitação maior foi a adsorção de Diuron pela semente de $M$. oleifera.

A partir de todas as análises realizadas, verificou-se que a adsorção máxima de Diuron da água foi de $67 \%$. Essa remoção foi obtida utilizando $0,5 \mathrm{~g}$ de massa de adsorvente, granulometria de $500 \mu \mathrm{m}, \mathrm{pH}$ 10 , temperatura de $45^{\circ} \mathrm{C}$ e velocidade de agitação de $200 \mathrm{rpm}$.

\section{CONSIDERAÇÕES FINAIS}

A eficiência de remoção de Diuron da água foi de $67 \%$ quando utilizada as sementes de $M$. oleifera como adsorvente natural.

Os parâmetros que foram significativos na adsorção do Diuron foram: massa de adsorvente, temperatura e velocidade de agitação. 
Os resultados experimentais satisfatórios da semente de $M$. oleifera indicam que ela é um material natural promissor para a remoção de Diuron. Ela pode ser considerada como uma alternativa eficiente e de baixo custo, já que sua preparação foi simples e não houve tratamento químico.

\section{REFERÊNCIAS}

CHEN, WEI-HSIANG; YOUNG, THOMAS $M$. Influence of nitrogen source on NDMA formation during chlorination of diuron. Water research, vol. 43, $\mathrm{n}^{\circ} 12, \mathrm{p}$. 3047-3056, 2009.

GIACOMAZZI, S.; COCHET, N. Environmental impact of diuron transformation: a review. Chemosphere, vol. 56, no 11, p. 1021-1032, 2004.

GOODDY, Daren C.; CHILTON, P. John; HARRISON, Ian. A field study to assess the degradation and transport of diuron and its metabolites in a calcareous soil. Science of the total environment, vol. $297, \mathrm{n}^{\circ} 1$, p. 67 83, 2002.

HOLMES, Glen. Australia's pesticide environmental risk assessment failure: The case of diuron and sugarcane. Marine pollution bulletin, vol. $88, \mathrm{n}^{\mathrm{o}} 1, \mathrm{p} .7-13$, 2014.

MCKAY, Gordon; OTTERBURN, M. S.; SWEENEY, A. G.The removal of colour from effluent using various adsorbentsIII.Silica: rate processes. WaterResearch, vol. 14, no 1, p. 15-20, 1980.

MINISTÉRIO DA SAÚDE DO BRASIL. Portaria $n^{\circ} 2914$ de 12 de dezembro de 2011. Dispõe sobre os procedimentos de controle e de vigilância da qualidade da água para consumo humano e seu padrão de potabilidade. Diário Oficial da União, 2011.

\section{AGRADECIMENTOS}

Ao $\mathrm{CNPq}$ pelo apoio financeiro. 